\title{
Functional identification of complex cells from spike times and the decoding of visual stimuli
}

\author{
Aurel A Lazar ${ }^{*}$, Nikul H Ukani, Yiyin Zhou \\ From 24th Annual Computational Neuroscience Meeting: CNS*2015 \\ Prague, Czech Republic. 18-23 July 2015
}

Neural circuits built with complex cells play a key role in modeling the primary visual cortex. The encoding capability of an ensemble of complex cells has not been systematically studied, however. Can visual scenes be reconstructed using the spike times generated by an ensemble of complex cells? Can the processing taking place in complex cells be identified with high accuracy? Processing by complex cells has the complexity of

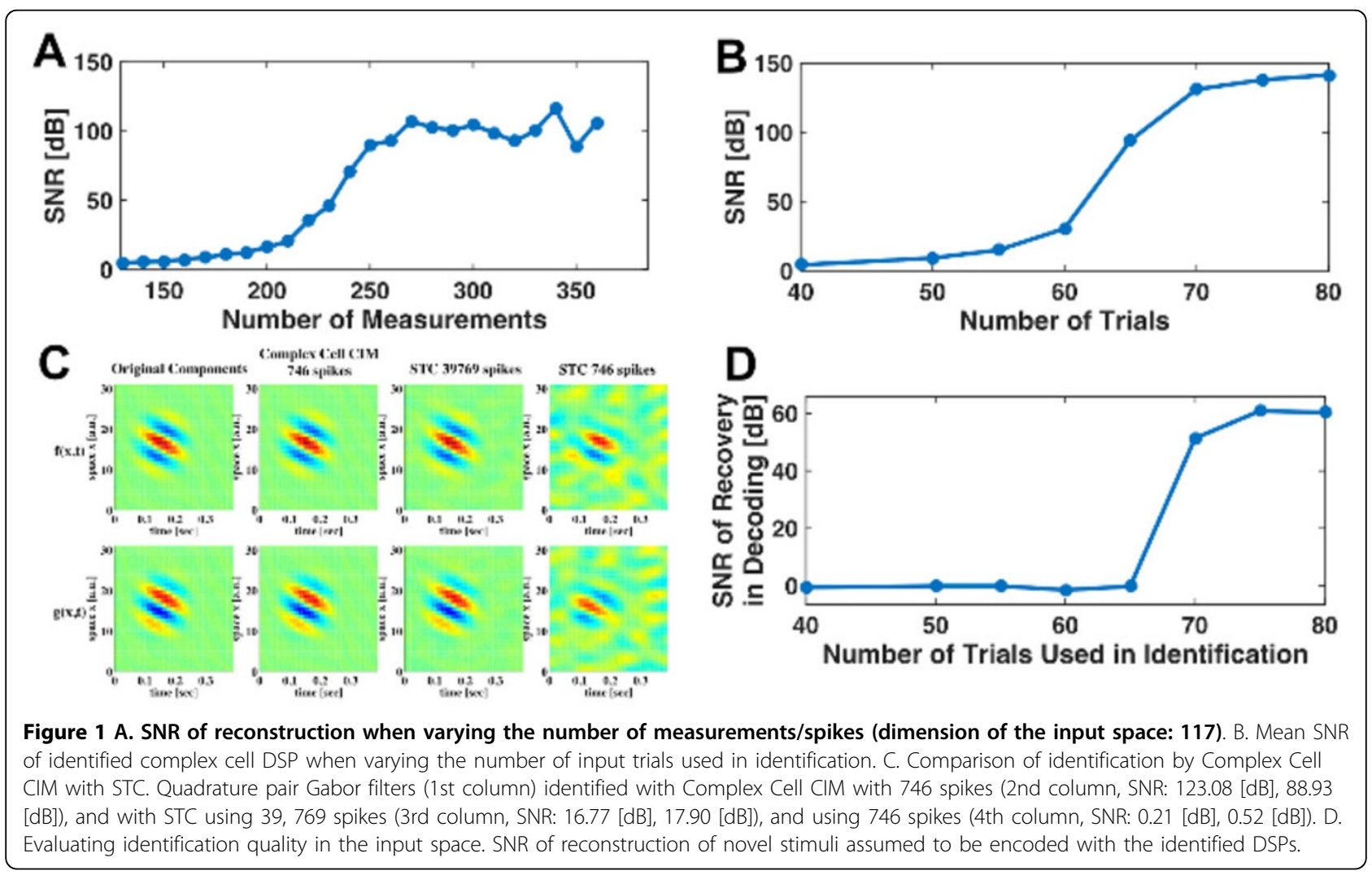

* Correspondence: aurel@ee.columbia.edu

Department of Electrical Engineering, Columbia University, New York, NY 10027, USA 
Volterra models [1]. General Volterra based models call, among others, for efficient functional identification and decoding algorithms.

We demonstrate that complex cells exhibit Volterra dendritic stimulus processors (Volterra DSPs) that are analytically and computationally tractable. Decoding and identification problems arising in neural circuits built with complex cells can be efficiently solved as rank minimization problems [2]. We provide (i) an algorithm that reconstructs the visual stimuli based on the spike times generated by circuits with widely employed complex cells models (Complex Cell Time Decoding Machines), and (ii) propose a mechanistic algorithm for functionally identifying the processing in complex cells using the spike times they generate (Complex Cell Channel Identification Machines). These algorithms are based on the key observation that the functional identification of processing in a single complex cell is dual to the problem of decoding stimuli encoded by an ensemble of complex cells.

In addition, we show that the number of spikes needed for perfect reconstruction of a band-limited stimulus is proportional to the dimension of the stimulus space rather than the square of its dimension, thereby reducing the required number of neurons/measurements to a physiologically plausible range. This result demonstrates that visual stimuli can be efficiently reconstructed from the amplitude information carried in the complex cells alone. Similar results obtained for identification establish the computational tractability of higher order Volterra DSPs. We provide examples of perfect reconstruction of space-time stimuli (Figure 1A) and examples of identification of complex cell DSPs (Figure 1B). We demonstrate that our identification algorithms substantially outperform algorithms based on spike-triggered covariance (STC) (Figure 1C). Finally, we evaluate our identification algorithms by reconstructing novel stimuli in the input space using identified Volterra DSPs (Figure 1D) [3].

\section{Acknowledgements}

The research reported here was supported by AFOSR under grant \#FA955012-1-0232.

Published: 18 December 2015

\section{References}

1. Lazar AA, Slutskiy YB: Spiking neural circuits with dendritic stimulus processors: encoding, decoding, and identification in reproducing kernel Hilbert space. J Comput Neurosci 2015, 38(1):1-24.

2. Candès EJ, Strohmer T, Voroninski V: PhaseLift: Exact and stable signal recovery from magnitude measurements via convex programming. Comm Pure Appl Math 2013, 66(8):1241-1274.

3. Lazar AA, Slutskiy YB, Zhou Y: Massively parallel neural circuits for stereoscopic color vision: Encoding, decoding and identification. Neural Networks 2015, 63:254-271.
doi:10.1186/1471-2202-16-S1-P300

Cite this article as: Lazar et al.: Functional identification of complex cells from spike times and the decoding of visual stimuli. BMC Neuroscience 2015 16(Suppl 1):P300.

\section{Submit your next manuscript to BioMed Central and take full advantage of:}

- Convenient online submission

- Thorough peer review

- No space constraints or color figure charges

- Immediate publication on acceptance

- Inclusion in PubMed, CAS, Scopus and Google Scholar

- Research which is freely available for redistribution 